\title{
A liquid biopsy-based method for the detection and quantification of circulating tumor cells in surgical osteosarcoma patients
}

\author{
HAOQIANG ZHANG ${ }^{12^{*}}$, PENG GAO $^{1 *}$, XIN XIAO $^{1 *}$, MICHAL HEGER $^{3,4^{*}}$, LEI GENG $^{1}$, BO FAN $^{1}$, \\ YULIN YUAN ${ }^{1}$, CHEN HUANG $^{1}$, GUOJING CHEN ${ }^{1}$, YAO LIU ${ }^{4}$, YONGCHEN HU ${ }^{5}$, \\ XIUCHUN YU ${ }^{6}$, SUJIA WU ${ }^{7}$, LING WANG ${ }^{8}$ and ZHEN WANG ${ }^{1}$ \\ ${ }^{1}$ Department of Orthopedics, Xijing Hospital, Fourth Military Medical University, Xi'an, Shaanxi 710032; \\ ${ }^{2}$ Department of Joint Surgery, General Hospital of Lanzhou Military Region, Lanzhou, Gansu 730050, P.R. China; \\ ${ }^{3}$ Department of Experimental Surgery, Academic Medical Center, University of Amsterdam, 1105AZ Amsterdam; \\ ${ }^{4}$ Membrane Biochemistry and Biophysics, Institute of Biomembranes, Utrecht University, 3584CH Utrecht, \\ The Netherlands; ${ }^{5}$ Department of Orthopedic Oncology, Tianjin Hospital, Tianjin 300210; ${ }^{6}$ Department of Orthopedics, \\ The General Hospital of Jinan Military Commanding Region, Jinan, Shandong 250031; ${ }^{7}$ Department of Orthopedics, \\ The General Hospital of Nanjing Military Commanding Region, Nanjing, Jiangsu 210008; ${ }^{8}$ Department of Vascular \\ and Endocrine Surgery, Xijing Hospital, Fourth Military Medical University, Xi'an, Shaanxi 710032, P.R. China
}

Received December 19, 2016; Accepted February 14, 2017

DOI: $10.3892 /$ ijo.2017.3905

\begin{abstract}
A method for the enumeration and quantification of osteosarcoma (OS) circulating tumor cells (CTCs) is currently not available. A correlation between the number of CTCs and progression-free survival (PFS) has been established for other cancers, but not for OS CTCs. A method was therefore developed for CTC quantification in OS and validated in a prospective cohort of surgical patients with primary and recurrent/metastatic OS ( $\mathrm{N}=23)$. Human OS cells, acting as CTCs, were enumerated from spiked human peripheral blood (PB) following erythrocyte and leukocyte depletion. The OS cells were quantified microscopically based on aneuploidy and a CK $18^{-} / \mathrm{CD} 45^{-}$phenotype. Aneuploidy was assayed by fluorescence in situ hybridization (FISH) using fluorescence-labeled alpha-satellite probes for the centromeres of chromosome (CEP 8). CK18 and CD45 phenotyping was performed with
\end{abstract}

Correspondence to: Professor Zhen Wang, Department of Orthopedics, Xijing Hospital, Fourth Military Medical University, Changle West Road 169, New City, Xi'an, Shaanxi 710032, P.R. China E-mail: wangzhen@fmmu.edu.cn

Professor Ling Wang, Department of Vascular and Endocrine Surgery, Xijing Hospital, Fourth Military Medical University, Changle West Road 169, New City, Xi'an, Shaanxi 710032, P.R. China

E-mail: vascular@fmmu.edu.cn

${ }^{*}$ Contributed equally

Key words: circulating tumor cell enumeration, immunocytochemistry and fluorescence in situ hybridization, progression-free survival, personalized medicine immunocytochemistry. HOS cells in spiked PB could be effectively retrieved with the FISH-based enumeration method, which was subsequently employed in an OS patient cohort. PB of recurrent/metastatic OS patients contained more CTCs than the PB of primary OS patients. OS patients with $\geq 2$ CTCs per $7.5 \mathrm{ml}$ of PB had worse PFS than patients whose PB contained $<2$ CTCs. In 2 cases, CTCs were present in PB of OS patients with negative X-ray and chest CT scans. In conclusion, our method was able to quantitate CTCs in liquid biopsies of OS patients. The number of CTCs has diagnostic and prognostic value.

\section{Introduction}

Sarcomas constitute cancers of mesenchymal origin and hence arise in tissue of the circulatory and lymphatic system as well as connective tissue such as cartilage and bone. Sarcomas represent $\sim 20 \%$ of pediatric solid malignancies and $<1 \%$ of adult solid malignancies (1). Of all sarcomas, $\sim 13 \%$ comprises malignant bone tumors of which $\sim 4 \%$ entails osteosarcoma (OS) (1). Although the incidence of OS is low, it has one of the most dismal survival rates of the pediatric cancers. Approximately $10-20 \%$ of patients present with metastatic disease at diagnosis and the 5-year overall survival is $\sim 70 \%$ for non-metastatic patients and $\sim 30 \%$ for metastatic patients (2-4). The survival rate is affected by the tumor site, increasing proportionally with the degree of necrosis from neoadjuvant chemotherapy, and decreases with increased age (5), tumor mass, expression of surface markers [P-glycoprotein (6), CXCR4 (7), and possibly HER2 (8)], number of metastases [particularly to the lungs (9)], and time to metastasis $(10,11)$.

A plethora of prognostic markers has been unraveled for OS in the last couple of years, although the intrinsic value of some of these markers is questionable inasmuch as the tumors exhibit a propensity to metastasize (12) and 
metastasis is detrimental to prognosis $(9,12,13)$. Moreover, a large portion of the currently available prognostic markers is derived from the primary tumor. However, these markers do not account for metastatic potential per se and may, at least in part, discount the critical effect of metastasis on prognosis. Circulatory markers have also been identified, including miR-29, miR-133b, miR-148a, miR-195, miR-196a/b, and miR-206 (14-18), but these also do not contain information on the cells that are de facto responsible for metastasis, i.e., the circulating tumor cells (CTCs) (19) and circulating cancer stem cells (CCSCs) (20-23).

Accordingly, a method that detects CTCs and CCSCs would be most useful in assessing metastatic potential in OS patients and rendering an accurate prognosis, as previously addressed for other types of cancer (24). However, the currently employed FDA-approved method (CellSearch system from Veridex) utilizes markers (EpCAM and cytokeratins) that are specific for CTCs of epithelial origin but not mesenchymal origin. Since sarcomas lack these markers, their detection with the CellSearch system is impossible. Although alternative methods for detecting sarcoma-derived CTCs have recently been developed, none exist for OS CTCs (19).

Consequently, the present study describes a method for the enumeration and quantification of CTCs from peripheral blood (PB) of OS patients based on abnormal chromosome numbers (aneuploidy) in CTCs rather than the surface epitopes. We recently validated this method for the detection of CTCs in breast cancer patients (25), and have therefore extended the method for the detection of OS CTCs in this in vitro and prospective clinical study. Accordingly, the CTCs were characterized by fluorescence in situ hybridization (FISH) in conjunction with immunocytochemistry for cytokeratin and CD45 to exclude epithelial and lymphocytic cells, respectively. Following methodological proof-of-concept, the number of CTCs in patients with primary OS were compared to the number of CTCs in patients with recurrent or metastatic OS. This analysis showed that the PB of the latter group contained more CTCs than the PB of primary OS patients. Finally, correlation analysis was performed on the number of CTCs in the patient's PB and progression-free survival (PFS), which revealed that OS patients with $\geq 2$ CTCs per $7.5 \mathrm{ml}$ of $\mathrm{PB}$ had worse PFS than patients whose PB contained $<2$ CTCs. We therefore concluded that the FISH/immunocytochemistry method was suitable to quantitate CTCs in liquid biopsies of OS patients and that the results may have prognostic value.

\section{Materials and methods}

The present study was conducted in accordance with the CONSORT 2010 checklist.

Cell culture. Human OS (HOS) cells and human hepatocellular carcinoma (HepG2) were purchased from the Cell Bank of the Chinese Academy of Sciences (Shanghai, China). The cell lines were authenticated and characterized by DNA fingerprinting, isozyme analysis, cell vitality analysis, and mycoplasm by the supplier. The cells were expanded and frozen in P10 aliquots to standardize the experiments.

HOS and HepG2 cells were cultured in RPMI-1640 medium (cat. no. 45000-396; VWR, Radnor, PA, USA) supplemented with $10 \%$ fetal bovine serum (FBS; Gibco/Life Technologies, Carlsbad, CA, USA) in T25 culture flasks (Corning, Manassas, VA, USA) at standard culture conditions (humidified atmosphere of $5 \% \mathrm{CO}_{2}$ and $95 \%$ air, $37^{\circ} \mathrm{C}$ ). HOS and HepG2 cells were subcultured at a ratio of 1:6 and 1:4, respectively, and used in experiments after reaching $\sim 95 \%$ confluence.

Leukocyte isolation from peripheral blood. PB (4 ml) was collected from a healthy volunteer (HZ) into EDTA tubes and mixed 1:3 (v/v) with red blood cell lysis buffer (ACK lysis buffer; Beyotime Institute of Biotechnology, Shanghai, China). After 5-min incubation at room temperature (RT), the samples were centrifuged at $150 \mathrm{x}$ g for $10 \mathrm{~min}$ at RT. The leukocytecontaining pellet was washed twice with phosphate-buffered saline (PBS) at the previously mentioned settings and resuspended in $4 \mathrm{ml}$ of PBS. The samples were directly assayed by flow cytometry as described in 'Flow cytometry'.

Flow cytometry. To show that HOS cells cannot be quantified with putative epithelial markers (CK18 and CD45), flow cytometry was performed on HOS cells following CK18 and CD45 antibody staining. HepG2 cells, which have an epithelial phenotype $\left(\mathrm{CK}_{18}{ }^{+} / \mathrm{CD} 45^{-}\right)$, and $\mathrm{PB}$-derived leukocytes $\left(\mathrm{CK} 18 / \mathrm{CD}^{+} 5^{+}\right)$were used as positive controls $(\mathrm{N}=3 /$ cell line, $\mathrm{N}=3$ for PB-derived leukocytes).

HOS and HepG2 cells were detached with trypsin/EDTA (cat. no. R-001-100; Gibco/Life Technologies) and washed once with medium at $300 \mathrm{x}$ g for $5 \mathrm{~min}$ at RT. Cells were subsequently resuspended in PBS. HOS and HepG2 cells were stained with PE/Cy7-conjugated mouse anti-human CD45 monoclonal antibodies (clone F10-89-4, cat. no. ab46729; Abcam, Cambridge, UK) and FITC-conjugated mouse antihuman cytokeratin 18 (CK18) monoclonal antibodies (clone DC-10, cat. no. ab72813; Abcam) for $30 \mathrm{~min}$ at RT in the dark, using $10 \mu \mathrm{g}$ of antibodies per $10^{6}$ cells. HepG2 cells $\left(10^{6}\right.$ cells $/ \mathrm{ml}$ PBS $)$ and leukocytes $\left(10^{5}\right.$ cells $/ \mathrm{ml}$ PBS $)$ were stained in a similar manner with anti-CK18 and anti-CD45 antibodies, respectively.

Cells were assayed by flow cytometry (FACSAria III; BD Biosciences, Franklin Lakes, NJ, USA). Ten thousand events were collected in the gated region and data were analyzed in FCS Express (De Novo Software, Glenndale, CA, USA).

In vitro CTC sample preparation. To establish in vitro proofof-concept of the CTC detection and quantification technique in a setting that emulated the clinical scenario, PB was spiked with cultured HOS cells. The cultured HOS cells, which provisionally functioned as CTCs, were subsequently enumerated from the spiked sample.

HOS cells were cultured as described in 'Cell culture', isolated as described in 'Flow cytometry', and diluted in PBS to a density of $3 \times 10^{3}$ cells $/ \mathrm{ml}$. The cells were added to blood within 5 min after harvesting.

PB was collected from healthy volunteers into $10-\mathrm{ml}$ EDTA Vacutainer tubes (Becton Dickinson, Franklin Lakes, NJ, USA). Next, $5 \mathrm{ml}$ of PB was spiked with $2.5 \mathrm{ml}$ of the HOS cell suspension to yield a final cell density of $10^{3}$ cells $/ \mathrm{ml}(\mathrm{N}=3$ replicates from 3 volunteers). The HOS cells were isolated as described in 'Isolation of HOS from spiked venous blood' and quantified as described in 'Enumeration of cultured HOS 
cells by FISH'. Informed consent was obtained from healthy volunteers before blood collection. The drawing of blood from healthy volunteers (including the healthy volunteer in 'Leukocyte isolation from peripheral blood' was approved by the Drug and Clinical Trial Ethics Committee, First Affiliated Hospital of The Fourth Military Medical University, and all experimental procedures were conducted in accordance with the institute's guidelines and regulations.

Isolation of HOS from spiked venous blood. The HOS-spiked blood samples $(7.5 \mathrm{ml})$ were centrifuged at $800 \mathrm{x} \mathrm{g}$ for $8 \mathrm{~min}$ at $25^{\circ} \mathrm{C}$ and the cell pellet was resuspended in $4 \mathrm{ml}$ of $1 \mathrm{X} \mathrm{hCTC}$ buffer (Cytelligen, San Diego, CA, USA). The cell suspension was centrifuged at $300 \mathrm{xg}$ for $5 \mathrm{~min}$ at $25^{\circ} \mathrm{C}$ and the resulting cell pellet was resuspended in $3 \mathrm{ml}$ of PBS. The cell suspension was incubated with $150 \mu \mathrm{l}$ of mouse anti-human CD45 monoclonal antibody-coated magnetic beads (Human CTC Immunofluorescence Staining kit, cat. no. IFH-LEA-001; Cytelligen) for $30 \mathrm{~min}$ at $25^{\circ} \mathrm{C}$ to tag leukocytes and placed onto a magnetic stand (MagneSphere Technology Magnetic Separation Stands, cat. no. CD4002; Promega, Madison, WI, USA) positioned at a tilted angle for $3 \mathrm{~min}$ at $25^{\circ} \mathrm{C}$. The leukocyte-bound beads were magnetically captured and the supernatant, i.e., the fraction containing the CTC cells, was transferred to another centrifuge tube and diluted with $1 \mathrm{X}$ hCTC buffer to a final volume of $45 \mathrm{ml}$. This suspension was subsequently washed three times $\left(650 \mathrm{x}\right.$ g for $5 \mathrm{~min}$ at $\left.25^{\circ} \mathrm{C}\right)$ to retain the pellet containing the CTCs in $\sim 100 \mu 1$ of buffer. The cell pellet was resuspended as indicated below and either subjected to FISH + immunocytochemistry or counted under fluorescence microscope to determine the retrieval efficiency.

The CTC-enriched cell pellet was resuspended in $200 \mu \mathrm{l}$ of fixative solution (Human Circulating Rare Cell Subtraction Enrichment kit, cat. no. SEH-001; Cytelligen) and CTCs were characterized by FISH in conjunction with immunocytochemistry as it is described in 'Enumeration of cultured HOS cells by FISH'.

For the retrieval efficiency study, HOS cells were cultured as described in 'Cell culture', isolated as described in 'Flow cytometry', and counted. The cells were diluted to a concentration of 100, 300, 500, 1,000, and 2,000 cells $/ \mathrm{ml}$ medium and fluorescently labeled (CYTO-ID Green long-term cell tracer kit; Enzo Life Sciences, Farmingdale, NY, USA) according to the manufacturer's instructions. Blood samples $(7.5 \mathrm{ml})$ were subsequently spiked with the fluorescently labeled HOS cells to a final count of 1, 3, 5, 10 and 20 cells/sample. Fluorescently labeled HOS cells were isolated as described above but not fixed. Finally, $200 \mu \mathrm{l}$ of the eluted HOS-containing sample was transferred to a microscope slide and coverslipped. Cells in the entire sample were counted by fluorescence microscopy (Nikon Eclipse 80i; Nikon Tokyo, Japan) using a FITC filter set. A modified Bland-Altman plot was constructed to describe the retrieval efficiency.

Enumeration of cultured HOS cells by FISH. For FISH, cells were permeabilized by the addition of $100 \mu \mathrm{l}$ of $0.1 \%$ Triton X-100 (Sigma Aldrich, St. Louis, MO, USA). Subsequently, the cells were gently vortexed and a $200-\mu 1$ aliquot was transferred onto a microscope slide. The slides were air-dried overnight at $37^{\circ} \mathrm{C}$, thereby affixing the cells onto the slide. Next, the cells were prehybridized $(0.1 \mathrm{M} \mathrm{HCl}$, $0.05 \%$ Triton X-100), washed in saline sodium citrate (2X SSC; $0.3 \mathrm{M} \mathrm{NaCl}$ and $0.034 \mathrm{M}$ sodium citrate) and subsequently with PBS, and fixed with formaldehyde (1\% in PBS). After washing (PBS, 2X SSC) and dehydration in graded steps of ethanol (70, 85 , and $100 \%)$, DNA was denatured in formamide $(70 \%$ in $2 \mathrm{X} \mathrm{SSC}, 70^{\circ} \mathrm{C}, 5 \mathrm{~min}$ ) and the sample was again dehydrated via graded steps of ethanol. Hybridization solution (Hybrisol VI; Oncor, Dallas, TX, USA) containing fluorescence-labeled alpha satellite probes for the centromeres of chromosome (CEP 8) ( $2 \mu \mathrm{g} / \mathrm{ml}$, Vysis CEP; Abbott Molecular, Abbott Park, IL, USA) was applied to each slide, which was coverslipped, sealed, and incubated overnight at $37^{\circ} \mathrm{C}$. A detailed CEP 8 FISH protocol can be found at the Abbott Molecular technical support website (http://www.abbottmolecular.com/contactus/ fishtechsupport/keyproductinformation/vysisproducts/cep. html).

After the FISH procedure, cells were immunostained with Alexa Fluor 488-conjugated mouse anti-human CK18 monoclonal antibodies (cat. no. HAB-001R1; Cytelligen) and Alexa Fluor 594-conjugated mouse anti-human CD45 monoclonal antibodies (cat. no. HAB-001R2; Cytelligen) for $1 \mathrm{~h}$. Samples were washed three times with PBS. Finally, nuclei were counterstained with 4-6-diamidino-2-phenylindole (DAPI)-containing mounting medium (cat. no. FSH-001R7; Cytelligen) and subsequently analyzed by fluorescence microscopy equipped with the respective filter sets for the Alexa Fluor dyes and DAPI (Nikon Eclipse 80i). Light microscopy was used to confirm the CTC morphology of aneuploidic cells.

HOS cells were characterized based on aneuploidy, DAPIpositive staining, negative staining for CD45 and CK18, and cell size and morphology (intact cells were round to oval). All cells on the microscope slide were analyzed by at least two pathologists. Inasmuch as non-cancerous cells in PB are amphiploid and mostly diploid, aneuploidic (triploidic, pentaploidic) cells were classified as HOS cells in accordance with previous studies (26-29).

Patients and study design. A prospective, cross-sectional, single center trial was conducted at the Xijing Hospital to evaluate the diagnostic and prognostic utility of CTCs in 23 patients from Shaanxi, Gansu, and Ningxia province who had been diagnosed with recurrent or metastatic OS between January 2010 and August 2014. The study was approved by the Drug and Clinical Trial Ethics Committee, First Affiliated Hospital of The Fourth Military Medical University and registered in a clinical trial management public platform (Chinese Clinical Trial Register, www.chictr.org.cn) under register ID ChiCTR-OOC-15005925 (registration date: 28 January 2015). Written informed consent was obtained from every patient before enrollment in the trial. The clinical procedures were conducted in accordance with the guidelines approved by the Drug and Clinical Trial Ethics Committee.

Diagnosis and staging was predicated on histological assessment of tissue biopsies by a pathologist. The disease status was assessed according to World Health Organization criteria (30) and the staging was performed based on the Enneking classification system (31). Only patients with conventional and small round-cell OS were included. The exclusion criteria were the following: i) patients did not understand the 

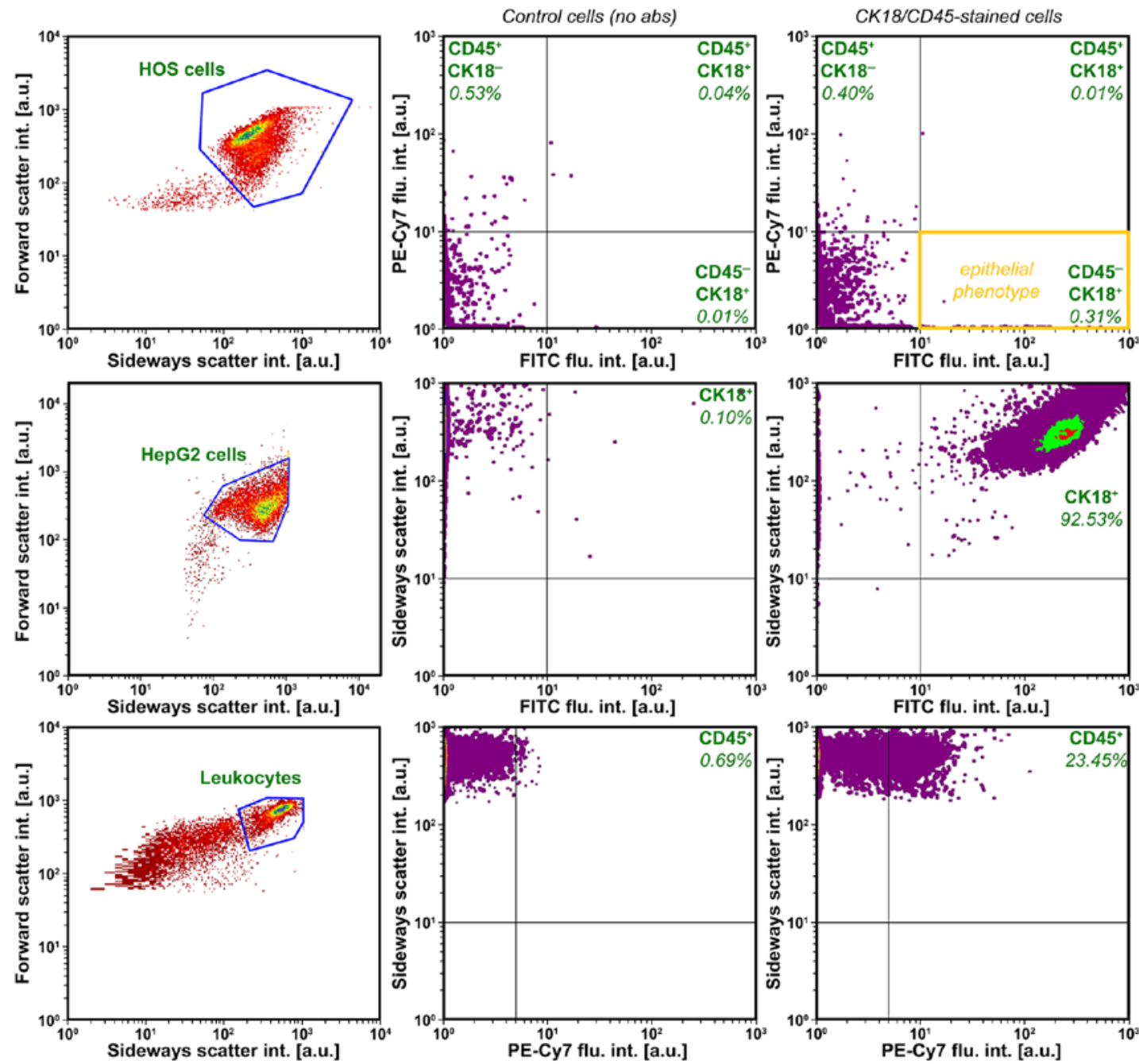

Figure 1. Flow cytometry density plots of CK18 and CD45 expression on HOS cells (top row, representative flow cytogram of N=3), HepG2 cells (middle row, positive control for $\mathrm{CK} 18$, representative flow cytogram of $\mathrm{N}=3$ ), and peripheral blood-derived leukocytes (bottom row, positive control for $\mathrm{CD} 45$, representative flow cytogram of $\mathrm{N}=3$ ). The gated cell populations are shown in the left column, unstained cells are shown in the middle column, and the fluorescent antibody-stained cells are shown in the right column. The percentage of cells in each quadrant is indicated relative to the entire cell population. HOS cells lack an epithelial phenotype (orange quadrant).

research purpose or did not give consent; ii) no or limited legal capacity to provide consent; iii) pregnancy or breastfeeding; iv) concurrent non-OS malignant tumors; v) serious complications, severe uncontrollable medical condition, or acute infection; and vi) medical history that could interfere with test results or increase the risk to patients. Following OS diagnosis, patients were screened for lung metastases using X-ray and chest CT.

Patient treatment and clinical monitoring. Limb salvage surgery was performed in all enrolled patients as previously described (32). All patients standardly received 4 cycles of first-line neoadjuvant chemotherapy with ifosfamide $\left(12 \mathrm{~g} / \mathrm{m}^{2}\right)$ and lobaplatin-adriamycin ( 45 and $60 \mathrm{mg} / \mathrm{m}^{2}$, respectively), starting immediately after diagnosis. After surgery patients received an additional 6-8 cycles of chemotherapy (same regimen as prior to surgery). The patients were followed up every 3 months for the first 2 years, and every 6 months thereafter for a maximum period of 5 years.

X-ray and chest CT scans were performed every 2 months during chemotherapy and every 3 months after the treatment to screen for lung and other metastases. Upon diagnosis of lung metastasis, the patients were scheduled for chemotherapy and local radiotherapy (gamma knife). In case of recurrence or local or single bone metastasis, the patients received surgery and chemotherapy. Patients with multifocal recurrence or metastasis were scheduled for either chemotherapy or treatment was withheld. First line chemotherapy was administered in all instances as described above.

Blood sampling and CTC enumeration. Blood samples were collected $1 \mathrm{~h}$ before the patients commenced chemotherapy. Venous blood $(7.5 \mathrm{ml})$ was collected into CellSave preservative tubes (Veridex LLC, Raritan, NJ, USA). The samples were stored at room temperature and processed according to the manufacturer's instructions within $72 \mathrm{~h}$ of collection. A second venous blood sample $(2 \mathrm{ml})$ was collected into an EDTA Vacutainer tube (BD Biosciences) to determine plasma alkaline phosphatase by routine clinical chemistry. CTCs were enumerated as described in 'Isolation of HOS from spiked venous blood' and 'Enumeration of cultured HOS cells by FISH'. 

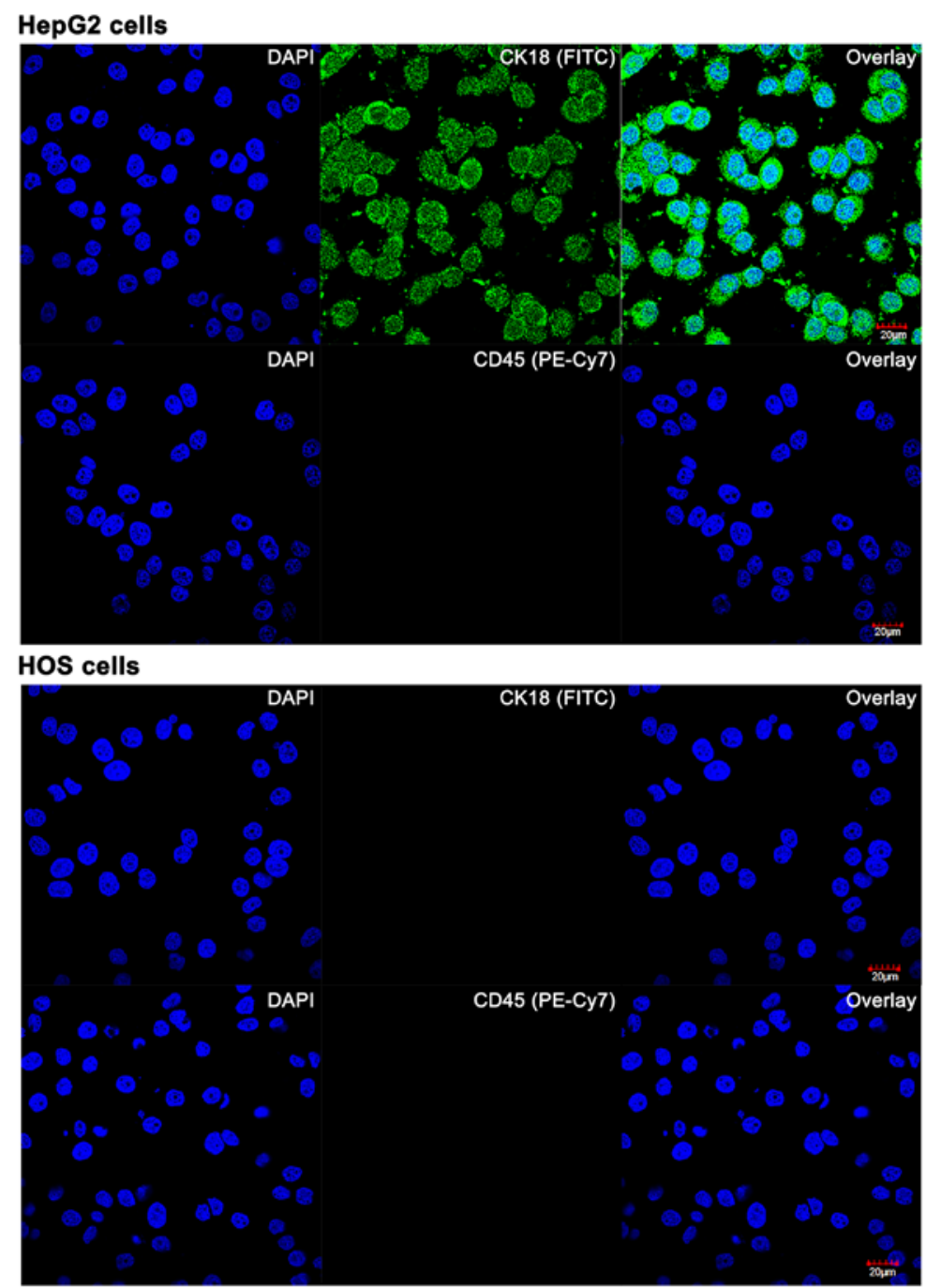

Figure 2. Confocal laser scanning images of cultured HepG2 and HOS cells stained with fluorophore-conjugated antibodies against cytokeratin 18 (CK18, top panels) and CD45 (bottom panels). Nuclei were stained with DAPI. A Leica SP5 confocal system was used. DAPI was excited at $\lambda_{\mathrm{ex}}=405 \mathrm{~nm}(15 \%$ of maximum output power), FITC and PE-Cy7 were excited at $\lambda_{\mathrm{ex}}=488 \mathrm{~nm}$ ( $60 \%$ of maximum output power). For DAPI, emission was measured at $\lambda_{\mathrm{em}}=461 \pm 50 \mathrm{~nm}$ (PMT at $467 \mathrm{~V}$ ). For FITC and PE-Cy7, emission was measured at $\lambda_{\mathrm{em}}=519 \pm 50 \mathrm{~nm}$ (PMT at $662 \mathrm{~V}$ ). All parameters were kept constant for the imaging.

Data and statistical analysis. Data analysis was performed in GraphPad Prism (GraphPad Software, San Diego, CA, USA). The normal distribution of data sets was confirmed with a D'Agostino-Pearson omnibus test. An unpaired homoscedastic Student's t-test was used to assess the statistical significance between ordinal variables. A $\mathrm{P} \leq 0.05$ was considered statistically significant. Data are reported as mean \pm standard deviation (SD).

To determine a CTC cut-off level that best predicts rapid progression of disease compared to slow progression, cut-off values of 1-5 CTCs per $7.5 \mathrm{ml}$ of PB were correlated with PFS for the 23 patients and analyzed using the Cox proportional hazards ratio. The $95 \%$ confidence interval (CI) was also calculated for this statistic.

The time interval between diagnosis and recurrence or metastasis was calculated on the basis of the patient's medical history and was used as a measure of PFS. PFS was based on $\mathrm{X}$-ray and chest CT scans and encompassed the elapsed time between the date on which OS was diagnosed and either the time of death or last follow-up. Survival curves were plotted as Kaplan-Meier estimators and compared using log-rank testing. The analyses of PFS were performed according to the intention-to-treat principle (33).

Correlation analysis was performed in SPSS (IBM, Armonk, NY, USA). Non-parametric Spearman rho analysis coupled with a two-tailed significance test was performed between the number of CTCs, gender, age, ethnic origin, alkaline phosphatase, recurrence or metastasis, follow-up time and survival. Categorical string variables were converted to numerical variables prior to the analysis (gender, male $=0$, female=1; ethnicity, Han=0, Hui=1; survival, yes=1, no=0; recurrence or metastasis, yes $=1, \mathrm{no}=0$ ).

\section{Results}

Detection of HOS cells by FISH: in vitro proof-of-concept. The first step was to demonstrate that HOS cells do not express epithelial and lymphocytic markers standardly used by the CellSearch system. Cultured HOS cells were assayed by flow cytometry following incubation with anti-CK18 and antiCD45 antibodies, whereby HepG2 cells and PB leukocytes were used as positive controls. As shown in Fig. 1, HOS cells 
Table I. Patient demographics, medical history, and disease characteristics $(\mathrm{N}=23$ patients).

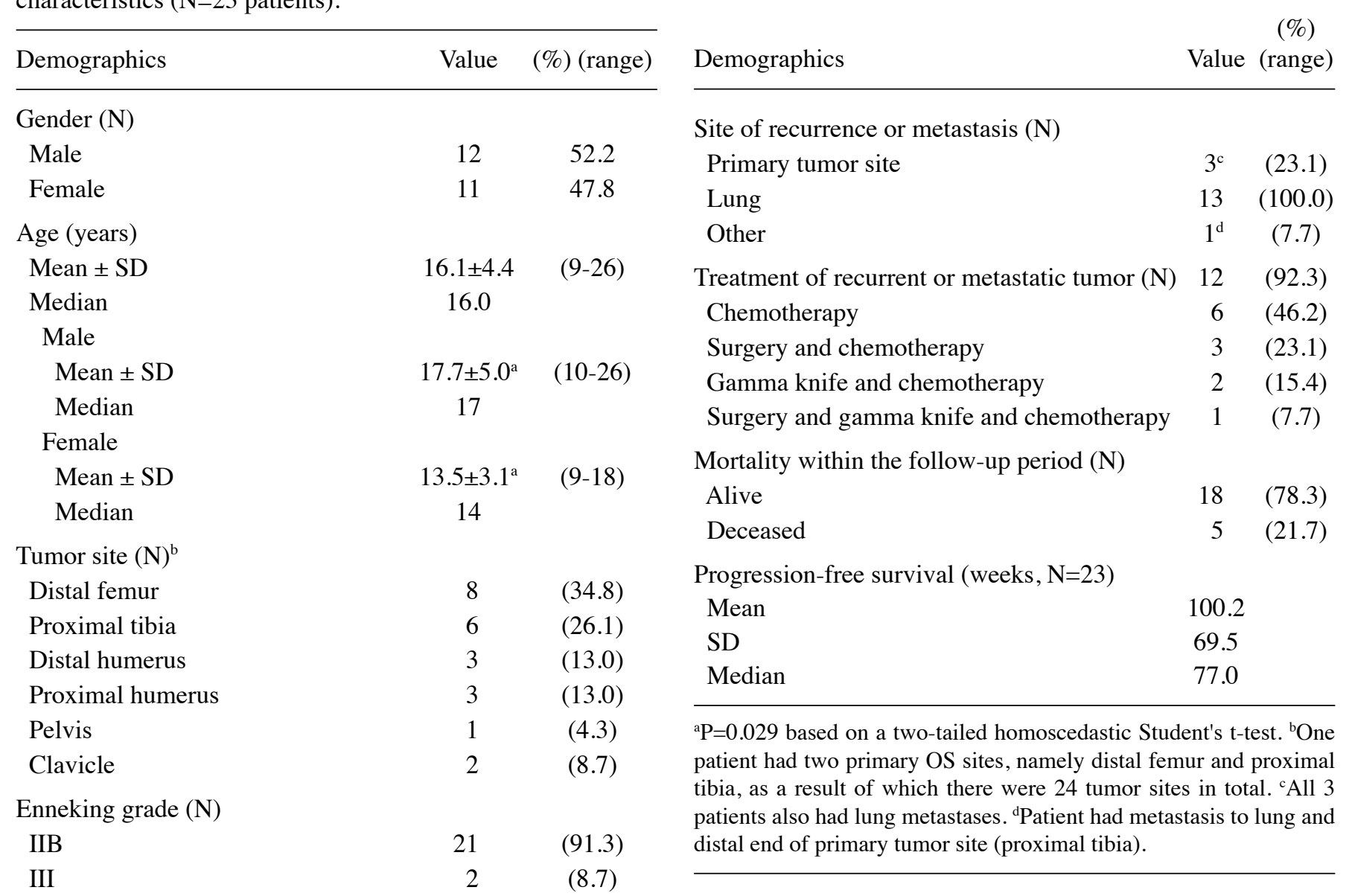

Type of OS $(\mathrm{N})$

$\begin{array}{lr}\text { Conventional OS } & 21 \\ \text { Small round-cell OS } & 2 \\ \text { Pathological fracture }(\mathrm{N}) & 1 \\ \text { Yes } & 22 \\ \text { No } & \end{array}$

Alkaline phosphatase $(\mathrm{N})$

Elevated

Normal (male 45-125 IU/1;

6

female 35-100 IU/1)

Male, mean \pm SD $(\mathrm{IU} / \mathrm{l})$

$169 \pm 54$

Female, mean \pm SD $($ IU/l)

$148 \pm 87$

(87-314)

(66-340)

Treatment of primary tumor $(\mathrm{N})$

Neoadjuvant chemotherapy

Yes

23

(100.0)

No

Surgery

Amputation

Limb salvage

(100.0)

Postoperative chemotherapy

Yes

No

23

Recurrence or metastasis $(\mathrm{N})$

Yes

No
Table I. Continued.

Site of recurrence or metastasis (N)

Progression-free survival (weeks, $\mathrm{N}=23$ )

${ }^{\mathrm{a}} \mathrm{P}=0.029$ based on a two-tailed homoscedastic Student's t-test. ${ }^{\mathrm{b}} \mathrm{One}$ patient had two primary OS sites, namely distal femur and proximal metastasis to lung and

were negative for both markers, whereas HepG2 cells (positive control for CK18, see also Fig. 2) and PB-derived leukocytes (positive control for CD45) exhibited a CK18 ${ }^{+}$and CD $45^{+}$ phenotype, respectively. These data indicate that the conventional CTC enumeration methods (usually based on $\mathrm{CK} 18^{+}$cell isolation following $\mathrm{CD}_{4} 5^{+}$cell depletion) are not suitable to isolate, detect and quantify CTCs of mesenchymal origin and that alternative techniques must be used.

The reliance on CK18 expression can be circumvented by staining chromatin (CEP 8) by FISH after erythrocyte and $\mathrm{CD} 45^{+}$cell depletion. To establish proof-of-concept of this OS CTC detection and quantification method, PB of healthy volunteers was spiked with cultured HOS cells and subjected to FISH and microscopic analysis. In the non-spiked PB of healthy patients, circulating non-leukocytic, non-erythrocytic cells were efficiently labeled by CEP 8 FISH, as evidenced by the diploid chromatin labeling (Fig. 3A-C) and stained positively for CK18 (data not shown). The CK18-/CD45- aneuploidic HOS cells (Fig. 1) in the spiked PB samples were easily retrieved on the basis of an aberrant number of fluorescent chromosomes (Fig. 3D-F) that coincided with negative CK18 and CD45 staining (Fig. 2).

Patient demographics, medical history, and disease characteristics. Next, the CTC enumeration method was validated in OS patients. A total of 23 eligible patients were enrolled between January 2010 and August 2014, of whom the demographics, medical history, and disease characteristics are 
A

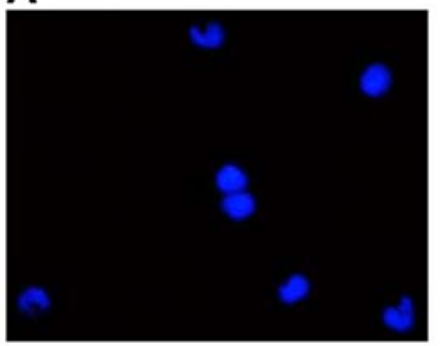

D

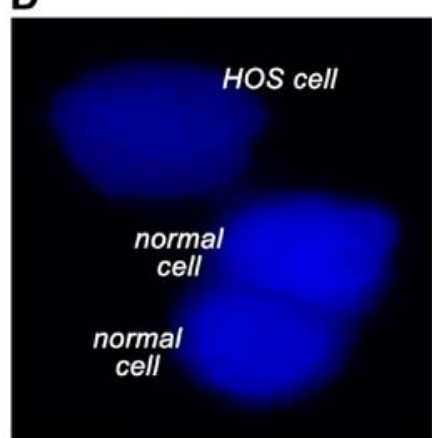

G

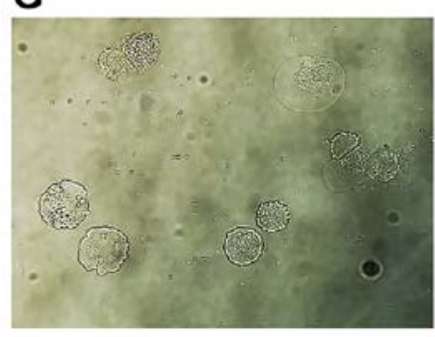

B

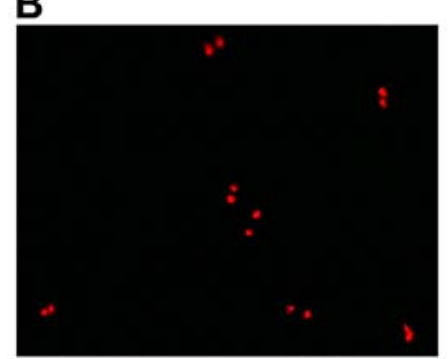

E

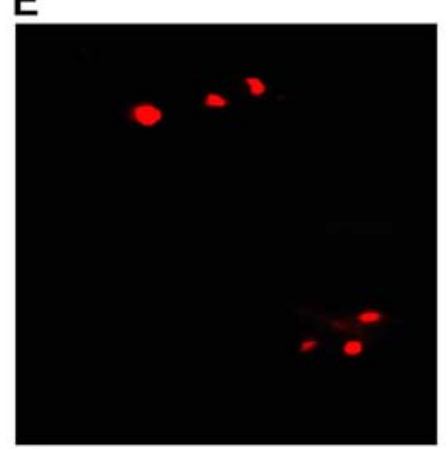

H

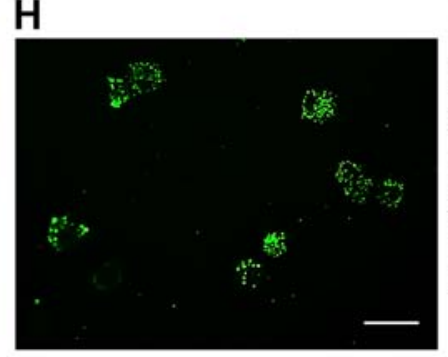

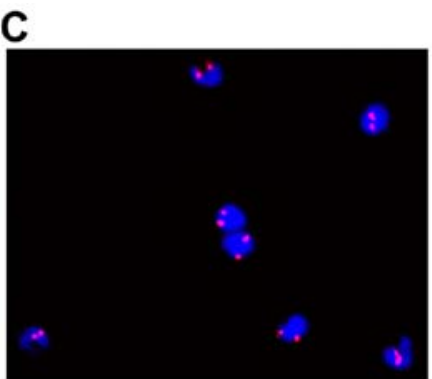

F
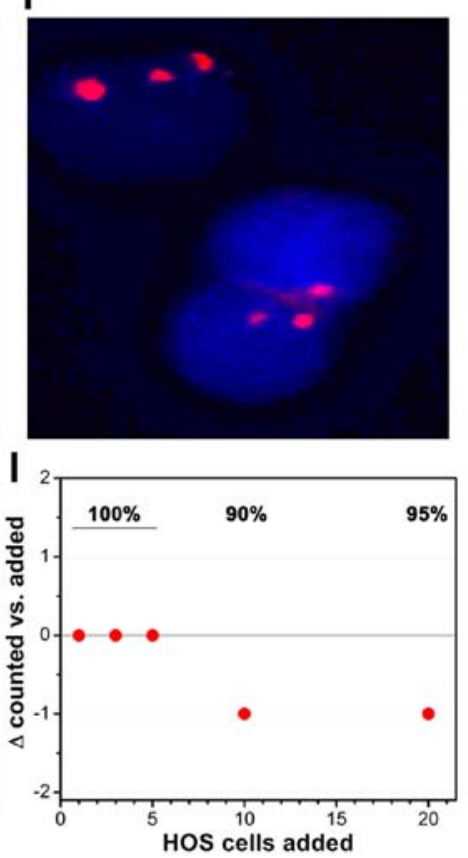

Figure 3. Retrieval of epithelial and HOS cells derived from spiked peripheral blood samples of healthy volunteers. The top row shows cells that were retrieved from non-spiked blood (representative images of $\mathrm{N}=3$ samples). Nuclei were stained with DAPI (blue fluorescence, A) and chromatin was stained with CEP 8 FISH (red fluorescence, B). The overlay is presented in (C). HOS cells in spiked peripheral blood could be distinguished from non-cancerous $\left(\mathrm{CK}^{-} 8^{+} / \mathrm{CD}^{-} 5^{-}\right.$) cells (normal cell) on the basis of the aneuploidic chromatin number (D-F) (representative images of $\mathrm{N}=3$ spiked samples). To determine retrieval efficiency of HOS cells using the isolation procedure employed for FISH, HOS cells were stained with the CYTO-ID Green long-term cell tracer (brightfield in G and fluorescence in $\mathrm{H}$ ) and added to $7.5 \mathrm{ml}$ of peripheral blood to a final concentration of 1, 3, 5, 10, and $20 \mathrm{HOS}$ cells/ml. Following isolation, the cells were counted by fluorescence microscopy in a 200- $\mu 1$ sample volume. (I) A modified Bland-Altman plot shows the retrieval efficacy of fluorescent HOS cells from the spiked PB samples. Retrieval rates are indicated as percentage at the top.

summarized in Table I. Information regarding the OS primary site and the site of recurrence or metastasis is provided in Fig. 4. Of the 23 patients, 16 patients $(69.6 \%)$ comprised ethnic Han (population of $\sim 1.25$ billion in China) and 7 patients (30.4\%) comprised ethnic Hui (population of $\sim 10.6$ million in China). These statistics suggest that ethnic Hui Chinese have a more considerable predilection for developing conventional and small round-cell OS than ethnic Han Chinese, particularly since the ratio of ethnic Hui:Han Chinese in the three provinces from which the patients were recruited is 0.5:99.4. The follow-up period ranged from 22 to 219 weeks (median of 77 weeks). The mean time between the first chest X-ray and CT scan and the follow-up X-ray and CT scan was $13 \pm 5$ weeks (range of 8-26 weeks, median of 10 weeks). Correlation analysis revealed a positive relationship between gender and survival $(\mathrm{Q}=0.505, \mathrm{P}=0.014$; female patients exhibited better survival), age and recurrence/metastasis $(\mathrm{Q}=0.492, \mathrm{P}=0.017$; older patients were more prone to recurrence/metastasis), and the number of CTCs and recurrence/metastasis $(\mathrm{Q}=0.605$, $\mathrm{P}=0.002$ ). A negative correlation was found between ethnicity and alkaline phosphatase $(\mathrm{Q}=-0.463, \mathrm{P}=0.026$; ethnic Han OS patients exhibited higher levels of alkaline phosphatase) (Table II).

Detection of CTCs in OS patients. To provide proof-of-concept of the enumeration technique for CTCs in OS patients, FISH and microscopic analysis were performed on OS patientderived PB in a similar manner as described for the HOS cell-spiked PB as described in 'Detection of HOS cells by FISH: in vitro proof-of-concept'. The CTCs were identified by means of aneuploidy and a DAPI-stained nucleus, which was further confirmed by their size and round-to-oval morphology using brightfield microscopy. As shown in Fig. 5, CTCs could be easily distinguished from non-cancerous cells on the basis of the primary parameters (fluorescence microscopy) alone.

Accordingly, CTCs were quantified in liquid biopsies of 23 eligible OS patients, the distribution of which is provided in Table III. The PB of 12 of the $13(92.3 \%)$ patients with recurrence or metastasis contained CTCs, with a mean \pm SD

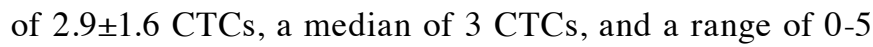


Table II. Correlation analysis between variables.

\begin{tabular}{|c|c|c|c|c|c|c|c|c|c|c|}
\hline & & & Gender & Age & Ethnicity & CTCs & ALP & Follow-up & $\begin{array}{c}\text { Recurrence/ } \\
\text { metastasis }\end{array}$ & Survival \\
\hline \multirow[t]{23}{*}{ Spearman's rho } & Gender & $\begin{array}{l}\text { Correlation } \\
\text { coefficient }\end{array}$ & 1.000 & $-0.429^{\mathrm{a}}$ & -0.066 & 0.013 & -0.230 & -0.033 & -0.389 & $0.505^{\mathrm{a}}$ \\
\hline & & Sig. (2-tailed) & & 0.041 & 0.765 & 0.952 & 0.292 & 0.882 & 0.066 & 0.014 \\
\hline & & $\mathrm{N}$ & 23 & 23 & 23 & 23 & 23 & 23 & 23 & 23 \\
\hline & Age & $\begin{array}{l}\text { Correlation } \\
\text { coefficient }\end{array}$ & & 1.000 & 0.208 & 0.357 & -0.093 & 0.214 & $0.492^{\mathrm{a}}$ & -0.232 \\
\hline & & Sig. (2-tailed) & & & 0.342 & 0.095 & 0.672 & 0.327 & 0.017 & 0.288 \\
\hline & & $\mathrm{N}$ & & 23 & 23 & 23 & 23 & 23 & 23 & 23 \\
\hline & Ethnicity & $\begin{array}{l}\text { Correlation } \\
\text { coefficient }\end{array}$ & & & 1.000 & 0.094 & $-0.463^{\mathrm{a}}$ & 0.014 & 0.199 & 0.120 \\
\hline & & Sig. (2-tailed) & & & & 0.669 & 0.026 & 0.949 & 0.363 & 0.587 \\
\hline & & $\mathrm{N}$ & & & 23 & 23 & 23 & 23 & 23 & 23 \\
\hline & CTCs & $\begin{array}{l}\text { Correlation } \\
\text { coefficient }\end{array}$ & & & & 1.000 & -0.058 & 0.019 & $0.605^{b}$ & 0.121 \\
\hline & & Sig. (2-tailed) & & & & & 0.791 & 0.931 & 0.002 & 0.582 \\
\hline & & $\mathrm{N}$ & & & & 23 & 23 & 23 & 23 & 23 \\
\hline & ALP & $\begin{array}{l}\text { Correlation } \\
\text { coefficient }\end{array}$ & & & & & 1.000 & -0.020 & 0.106 & -0.238 \\
\hline & & Sig. (2-tailed) & & & & & & 0.927 & 0.631 & 0.273 \\
\hline & & $\mathrm{N}$ & & & & & 23 & 23 & 23 & 23 \\
\hline & Follow-up & $\begin{array}{l}\text { Correlation } \\
\text { coefficient }\end{array}$ & & & & & & 1.000 & 0.126 & 0.088 \\
\hline & & Sig. (2-tailed) & & & & & & & 0.567 & 0.691 \\
\hline & & $\mathrm{N}$ & & & & & & 23 & 23 & 23 \\
\hline & $\begin{array}{c}\text { Recurrence/ } \\
\text { metastasis }\end{array}$ & $\begin{array}{l}\text { Ccorrelation } \\
\text { coefficient }\end{array}$ & & & & & & & 1.000 & -0.250 \\
\hline & & Sig. (2-tailed) & & & & & & & & 0.251 \\
\hline & & $\mathrm{N}$ & & & & & & & 23 & 23 \\
\hline & Survival & $\begin{array}{c}\text { Correlation } \\
\text { coefficient } \\
\text { Sig. (2-tailed) }\end{array}$ & & & & & & & & 1.000 \\
\hline & & $\mathrm{N}$ & & & & & & & & 23 \\
\hline
\end{tabular}

${ }^{\mathrm{a} C}$ Correlation is significant at the 0.05 level (2-tailed). ${ }^{\mathrm{b}}$ Correlation is significant at the 0.01 level (2-tailed). Significant correlations are shown in bold text.

CTCs per $7.5 \mathrm{ml} \mathrm{PB}$. In contrast, 3 of the $10(30.0 \%)$ patients with primary OS had no CTCs in their PB, with a mean \pm SD of 1.6 $\pm 1.3 \mathrm{CTCs}$, a median of $1 \mathrm{CTC}$, and a range of $0-4$ CTCs per $7.5 \mathrm{ml} \mathrm{PB} \mathrm{(P=0.044} \mathrm{vs.} \mathrm{the} \mathrm{recurrence/metastasis}$ group) (Fig. 6A). The amount of CTCs was further specified per primary OS site for the patients with no recurrence/ metastasis and the patients with recurrence/metastasis in Fig. 6B.

Prognostic value of CTC-based liquid biopsies for progression-free survival. The analysis revealed that, at a cut-off of 2 CTCs per $7.5 \mathrm{ml}$ of $\mathrm{PB}$, the Cox proportional hazards ratio reached a plateau relative to the higher cut-off values, indicating the level at which the cut-off should be set. At this cut-off, the hazard ratio (log-ranked) was 4.091 and the 95\% CI of the hazards ratio was 1.075-9.684. Patients with $\geq 2$ CTCs per $7.5 \mathrm{ml}$ of PB had a median PFS of 440 days compared to 547 days in patients with 0 or $1 \mathrm{CTCs}$ per $7.5 \mathrm{ml}$ PB ( $\mathrm{P}=0.0416)$ (Fig. 7). Consequently, a cut-off of 2 CTCs per $7.5 \mathrm{ml}$ of $\mathrm{PB}$ should be employed to distinguish patients with unfavorable prognosis from patients with a more favorable prognosis. 


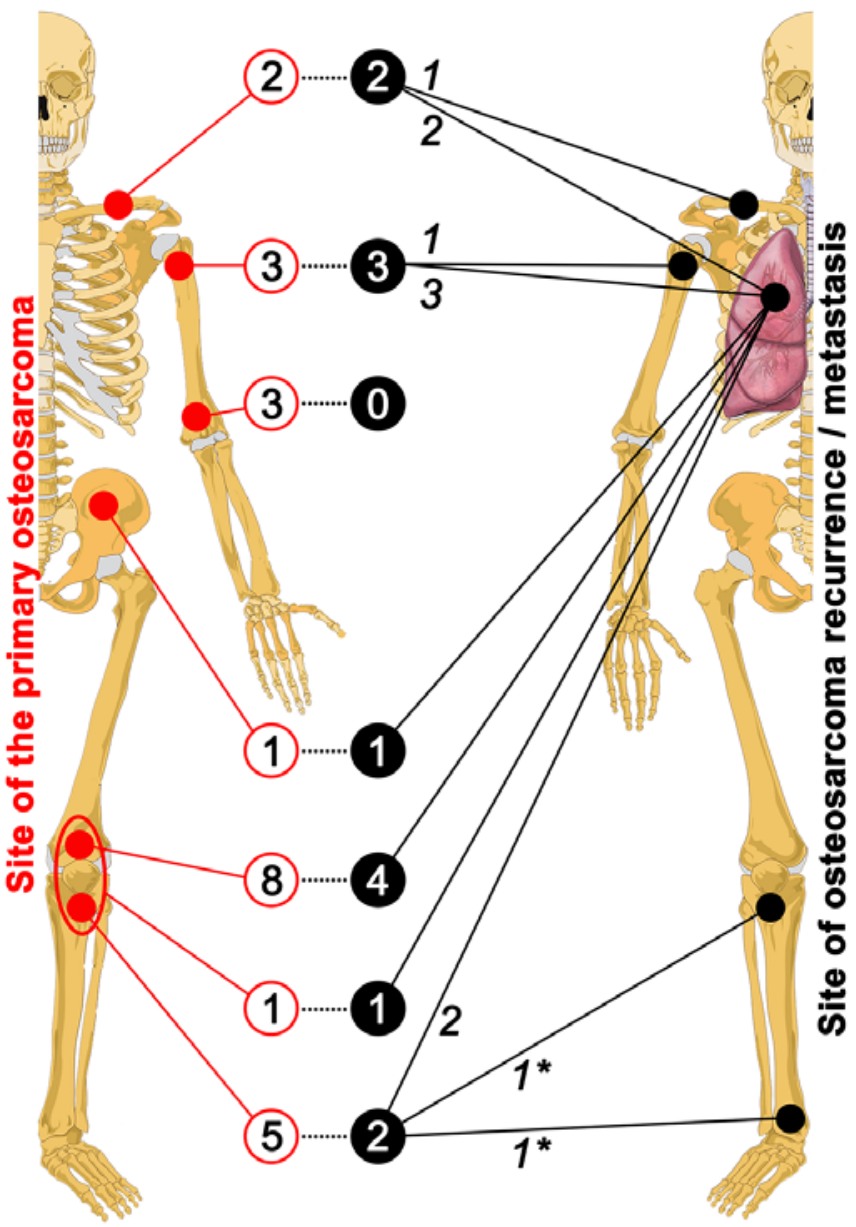

Figure 4. Anatomical map of the primary site of the OS in the entire patient population ( $\mathrm{N}=23$, left skeleton) and the site at which recurrence or metastasis occurred (in 13 of 23 patients, right skeleton). The numbers in red open circles indicate the tumor incidence at the corresponding location (solid red circles). The encircled area at the distal femur and proximal tibia represent the concurrence of these tumors in 1 patient. The numbers in solid black circles are linked (dotted line) to the tumor incidence and location in red open and solid circles, respectively, and indicate how many of those tumors recurred or metastasized. For example, none of the 3 tumors in the distal humerus recurred or metastasized. The location at or to which the tumors recurred or metastasized is provided by the solid black lines connected to the solid black circles. The numbers in italics indicate the number of recurrences or metastases to the respective location. Readers should note that, in case of metastasis, all OS metastasized to the lungs and that some primary tumors both recurred and metastasized (e.g., OS in the clavicle, proximal humerus and proximal tibia). The asterisks indicate recurrence and metastasis in the same patient.

Table III. Distribution of the number of CTCs detected in OS patients.

\begin{tabular}{lcr}
\hline No. of CTCs & No. of cases & $\%$ \\
\hline 0 & 3 & 13.0 \\
1 & 5 & 21.7 \\
2 & 5 & 21.7 \\
3 & 3 & 13.0 \\
4 & 5 & 21.7 \\
$\geq 5$ & $2(5,5)^{\mathrm{a}}$ & 8.7 \\
Total & 23 & 100.0 \\
\hline
\end{tabular}

${ }^{a}$ The actual number of CTCs found in these cases per $7.5 \mathrm{ml}$ of PB.

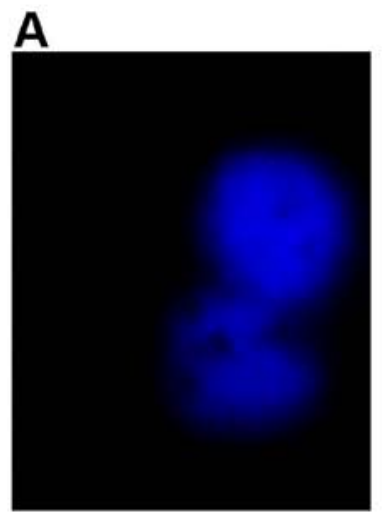

B
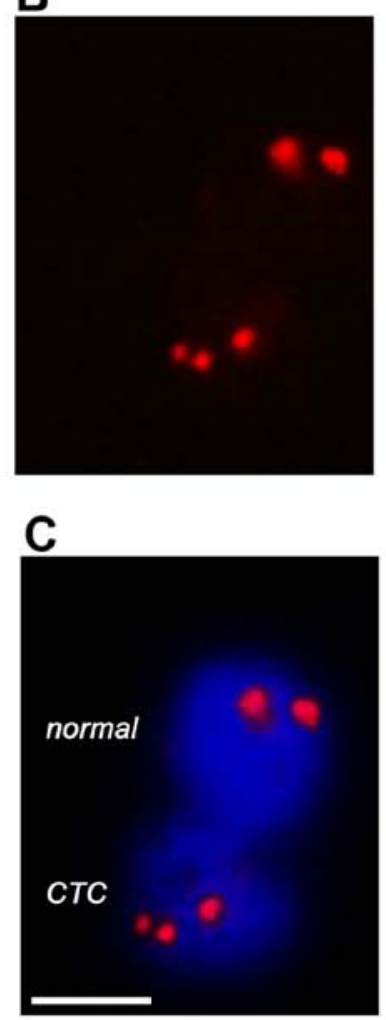

D

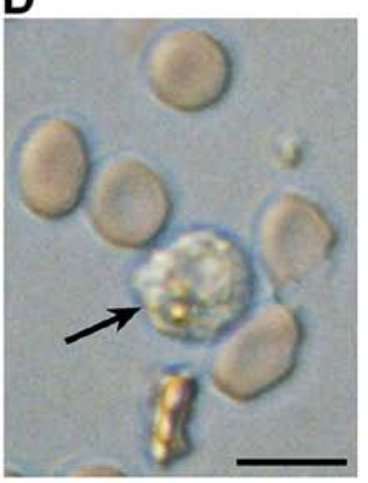

Figure 5. FISH and microscopic analysis of CTCs enriched from the peripheral blood of OS patients. With fluorescence microscopy (A-C), CTCs were clearly distinguished from healthy epithelial cells by the number of fluorescently stained chromosomes, which exhibited aneuploidy (in this example, 3 chromosomes) as opposed to diploidy. Cells were stained with DAPI (A) to visualize nuclei [and exclude residual red blood cells (RBCs) from analysis], whereas chromatin was stained with fluorescent CEP 8 probes (B, red). An overlay is provided in (C). Scale bar, $10 \mu \mathrm{m}$. (D) A brightfield image is shown to illustrate the morphology and relative size of CTCs (arrow) vs. residual RBCs in the sample. Scale bar, $15 \mu \mathrm{m}$. 
A

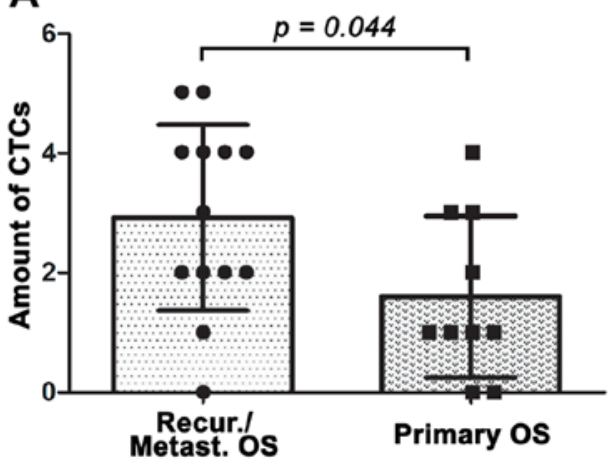

B

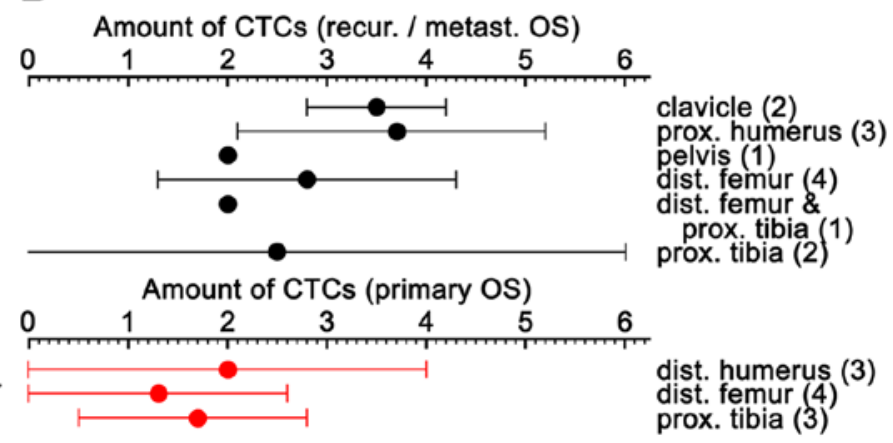

Figure 6. Summary of the amount of CTCs detected in the OS patient population (N=23). (A) The amount of CTCs in the group of patients with recurrence or metastasis vs. the group of patients with primary OS ( $\mathrm{N}=13$ and 10 , respectively). A statistically significant difference was found between the groups ( $\mathrm{P}=0.044$, unpaired homoscedastic Student's t-test). (B) The amount of CTCs per anatomical location of the primary tumor (right) in the group of patients with recurrence or metastasis versus the group of patients with primary OS. The patient numbers are indicated in parentheses. The site to at which the tumors recurred or to which the tumors metastasized is detailed in Fig. 5. All data are plotted as mean \pm SD.

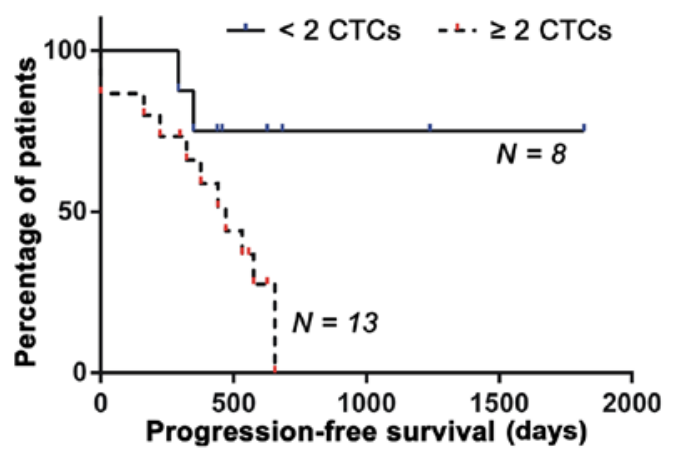

Figure 7. Kaplan-Meier plot of progression-free survival in OS patients using a cut-off of 2 CTCs per $7.5 \mathrm{ml}$ peripheral blood. The $\geq 2$ CTCs group had a median progression-free survival of 440 days, whereas the $<2$ CTCs group had a median progression-free survival of 547 days $[\mathrm{P}=0.0416$, hazards ratio $(\log$-rank $)=4.091,95 \% \mathrm{CI}$ of hazards ratio, 1.075-9.684].

\section{Discussion}

A method was developed to enumerate CTCs with a nonepithelial phenotype from liquid biopsies and to quantify the OS CTCs on the basis of aneuploidy by fluorescence microscopy. The FISH technique proved a viable alternative for the CellSearch method, which is based on the depletion of $\mathrm{CD} 45^{+}$cells and subsequent quantification of $\mathrm{CK} 18^{+}$cells, for the quantification of CTCs of epithelial origin. The presented technique is straightforward and can be clinically standardized, given that an outcome can be rendered within a day, all reagents are commercially available, standard clinical laboratories are equipped with the necessary equipment, and the quantification does not require special training or expertise. In addition to validating the FISH method in a population of OS patients, it was demonstrated that: i) the PB of recurrent/ metastatic OS patients contained more CTCs than the PB of primary OS patients; and ii) the number of CTCs in liquid biopsies has prognostic value, whereby $\geq 2$ CTCs per $7.5 \mathrm{ml}$ of PB was associated with significantly shorter PFS than when the liquid biopsy contained 1 or no CTCs.

Numerous tumor biopsy-based markers have been found for OS and include miR-9, miR-132, miR-145, miR-183,
miR-223, and miR-128 in combination with transcript levels of phosphatase and tensin homolog (PTEN) (34-39), the DNA mismatch repair proteins MutS protein homolog 2 (MSH2) and MSH6 (40), hypermethylated DNA of ARF tumor suppressor (p14 ${ }^{\mathrm{ARF}}$ ) and estrogen receptor $\alpha(41)$, the transcription factor SOX9 (42), RAC- $\beta$ serine/threonine-protein kinase (AKT2) (43), periostin (44), neuropilin-1 (45), glucose transporter protein 1 (GLUT-1) (46), and polymeric immunoglobulin receptor (pIgR) (47), amongst others. However, these markers are derived from the primary OS site and therefore discount metastases, which are important determinants for PFS $(9,12,13)$. The same applies to the circulatory markers (mainly miRs) alluded to in the introduction. Although these markers confirm the diagnosis rendered with standard imaging- and histological techniques (that are already very accurate for the diagnosis of OS) and have prognostic value, they do not contain information on the cells that are mainly responsible for PFS, namely the CTCs and CCSCs (19-23). CTC enumeration from liquid biopsies does contain this information, has prognostic value, and merely requires minimally invasive sampling and a simple enumeration and quantification protocol.

In addition to establishing and validating a novel CTC quantification method, the study demonstrated that a strong relationship exists between the amount of CTCs and OS recurrence/metastasis $(\mathrm{Q}=0.605, \mathrm{P}=0.002)$ and that CTCs are predictive for PFS in OS patients. This is in agreement with published literature on the predictive capacity of CTCs regarding recurrence/metastasis and PFS in other types of cancer, including (metastatic) breast cancer. Studies have demonstrated that CTCs are a strong independent predictor of survival among women with recurrent metastatic breast cancer (48) and that the presence and elevated levels of CTCs are associated with poorer prognosis (49). Moreover, CTCs have been employed to monitor disease status following an intervention (50), which is now theoretically possible for OS as well with the FISH/microscopy method.

Most importantly, CTCs may be used to rule out false negative results obtained with X-ray and chest CT, which are limited in spatial resolution and therefore unable to detect small-volume metastases. To exemplify this, two patients 
A

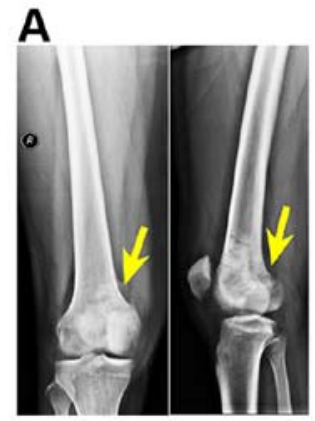

$\mathbf{E}$

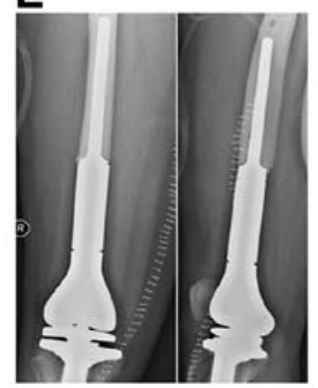

B

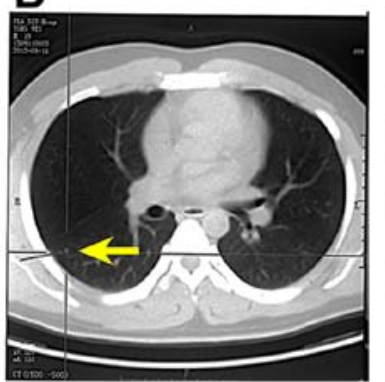

$\mathbf{F}$

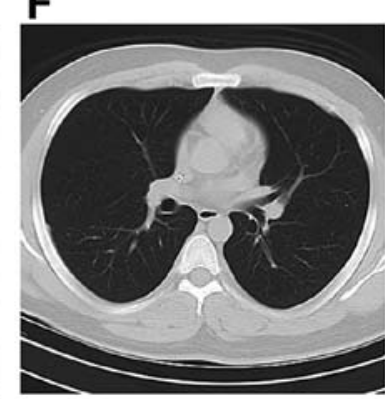

C

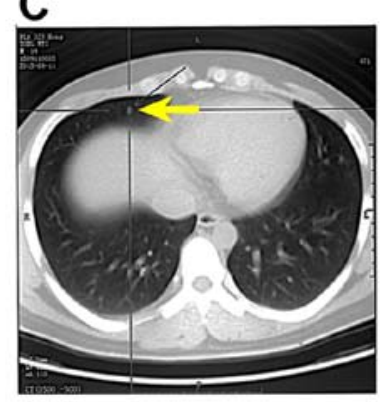

G

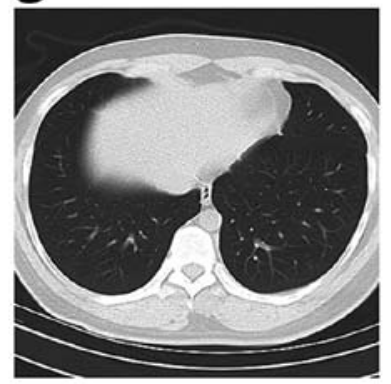

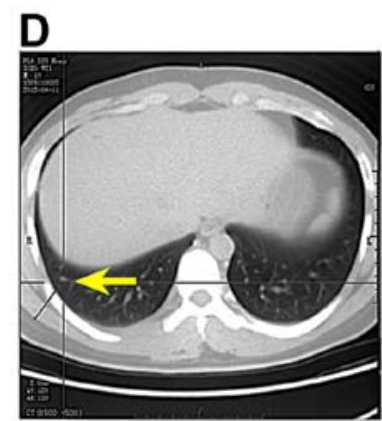

H

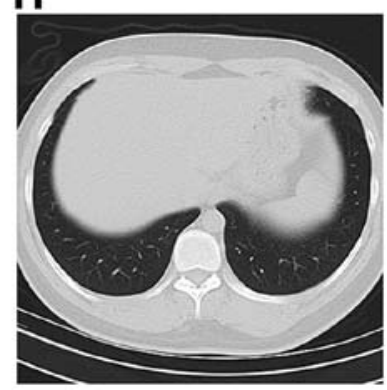

Figure 8. X-ray and chest CT scans of a primary metastatic osteosarcoma patient. Upon OS diagnosis (A, arrow), there were three metastases in the right lung (B-D, arrows). After neoadjuvant chemotherapy, tumor segment resection, and prosthetic replacement (E), no metastases were observed on the chest CT scans (F-H, which correspond to the $\mathrm{x}-\mathrm{y}$ cross-sectional planes where metastases were found before neoadjuvant chemotherapy and limb salvage surgery in B-D). Nevertheless, 4 CTCs were found in this patient's liquid biopsy.

in the study cohort with primary metastatic OS to the lungs (Fig. 8A-D) exhibited negative chest CT following surgery and chemotherapy (Fig. 8E-H), but their PB contained CTCs. Despite the favorable diagnosis, the patients were by no means disease-free. Evidently, the gold standard methods are incapable of providing enough information of the state of the malignancy or accurately predict the clinical outcome, which is in conformity with the fact that primary metastatic OS patients have poor prognosis despite the good response to chemotherapy. To improve the survival of OS patients, it is important to employ feasible diagnostic methods with which recurrence and/or metastatic potential can be determined and the antitumor treatment efficacy can be accurately monitored.

The CTC enumeration and quantification method from liquid biopsies fits well in a personalized medicine approach, where information on each patient's unique clinical condition is exploited to implement early disease intervention based on more informed medical decisions. The presence of CTCs in PB of OS patients is associated with poor clinical outcome in both primary and metastatic malignancies. The CTC profile may therefore steer the selection of effective treatment strategies in early and advanced OS. Moreover, CTC quantification in OS patients may be utilized as a (personalized) therapy monitoring tool (51) inasmuch as changes in CTC count generally reflect therapeutic response after already the first cycle of chemotherapy.

Readers should be aware that this prospective study is associated with some limitations. First, the method should be validated in a multi-center prospective clinical trial and include larger patient cohorts. Specifically, the $\geq 2$ CTC cut-off should be subjected to more robust analysis in both primary OS and metastatic/recurrent OS patient populations. Furthermore, the sensitivity and specificity of the technique should be addressed. Finally, the relationship between the number of CTCs and tumor stage should be determined and the follow-up times should be increased and entail a higher monitoring frequency to unequivocally corroborate that CTC detection can eliminate false negatives obtained with gold standard diagnostic techniques and to establish its true prognostic power. After these steps have been undertaken, the CTC method can be expanded towards other applications, such as therapeutic response monitoring, elucidation of chemoresistance mechanisms, and CTC genomics and proteomics studies to gain insight into OS CTC biology and biochemistry.

\section{Acknowledgements}

We are grateful for the technological support provided by the Shanghai Biotecan Clinical Laboratory. The present study was supported by the National Natural Science Fund of China (nos. 31170914 and 81272899) and the Discipline Booster Plan of Xi Jing Hospital (no. XJZT12Z07).

\section{References}

1. Burningham Z, Hashibe M, Spector L and Schiffman JD: The epidemiology of sarcoma. Clin Sarcoma Res 2: 14, 2012.

2. Ferrari S and Palmerini E: Adjuvant and neoadjuvant combination chemotherapy for osteogenic sarcoma. Curr Opin Oncol 19: 341-346, 2007.

3. Jaffe N: Adjuvant chemotherapy in osteosarcoma: An odyssey of rejection and vindication. Cancer Treat Res 152: 219-237, 2009.

4. Chou AJ, Geller DS and Gorlick R: Therapy for osteosarcoma: Where do we go from here? Paediatr Drugs 10: 315-327, 2008.

5. Haddox CL, Han G, Anijar L, Binitie O, Letson GD, Bui MM and Reed DR: Osteosarcoma in pediatric patients and young adults: a single institution retrospective review of presentation, therapy, and outcome. Sarcoma 2014: 402509, 2014.

6. Serra M, Scotlandi K, Manara MC, Maurici D, Benini S, Sarti M, Campanacci $\mathrm{M}$ and Baldini N: Analysis of P-glycoprotein expression in osteosarcoma. Eur J Cancer 31A: 1998-2002, 1995. 
7. Perissinotto E, Cavalloni G, Leone F, Fonsato V, Mitola S, Grignani G, Surrenti N, Sangiolo D, Bussolino F, Piacibello W, et al: Involvement of chemokine receptor 4/stromal cell-derived factor 1 system during osteosarcoma tumor progression. Clin Cancer Res 11: 490-497, 2005.

8. Gill J, Geller D and Gorlick R: HER-2 involvement in osteosarcoma. Adv Exp Med Biol 804: 161-177, 2014.

9. Jeffree GM, Price CH and Sissons HA: The metastatic patterns of osteosarcoma. Br J Cancer 32: 87-107, 1975.

10. Moore DD and Luu HH: Osteosarcoma. Cancer Treat Res 162: 65-92, 2014.

11. Xing D, Qasem SA, Owusu K, Zhang K, Siegal GP and Wei S: Changing prognostic factors in osteosarcoma: Analysis of 381 cases from two institutions. Hum Pathol 45: 1688-1696, 2014

12. Dunn D and Dehner LP: Metastatic osteosarcoma to lung: A clinicopathologic study of surgical biopsies and resections Cancer 40: 3054-3064, 1977.

13. Salah S, Ahmad R, Sultan I, Yaser S and Shehadeh A: Osteosarcoma with metastasis at initial diagnosis: Current outcomes and prognostic factors in the context of a comprehensive cancer center. Mol Clin Oncol 2: 811-816, 2014.

14. Hong Q, Fang J, Pang Y and Zheng J: Prognostic value of the microRNA-29 family in patients with primary osteosarcomas. Med Oncol 31: 37, 2014

15. Zhang C, Yao C, Li H, Wang G and He X: Serum levels of microRNA-133b and microRNA-206 expression predict prognosis in patients with osteosarcoma. Int J Clin Exp Pathol 7: 4194-4203, 2014

16. Ma W, Zhang X, Chai J, Chen P, Ren $P$ and Gong M: Circulating miR-148a is a significant diagnostic and prognostic biomarker fo patients with osteosarcoma. Tumour Biol 35: 12467-12472, 2014

17. Cai H, Zhao H, Tang J and Wu H: Serum miR-195 is a diagnostic and prognostic marker for osteosarcoma. J Surg Res 194 505-510, 2015

18. Zhang $\mathrm{C}$, Yao $\mathrm{C}$, Li H, Wang $\mathrm{G}$ and $\mathrm{He} \mathrm{X}$ : Combined elevation of microRNA-196a and microRNA-196b in sera predicts unfavorable prognosis in patients with osteosarcomas. Int J Mol Sci 15 : 6544-6555, 2014.

19. Chang L, Asatrian G, Dry SM and James AW: Circulating tumor cells in sarcomas: A brief review. Med Oncol 32: 430, 2015

20. Lapidot T, Sirard C, Vormoor J, Murdoch B, Hoang T, CaceresCortes J, Minden M, Paterson B, Caligiuri MA and Dick JE: A cell initiating human acute myeloid leukaemia after transplantation into SCID mice. Nature 367: 645-648, 1994

21. Yang ZF, Ngai P, Ho DW, Yu WC, Ng MN, Lau CK, Li ML, Tam KH, Lam CT, Poon RT, et al: Identification of local and circulating cancer stem cells in human liver cancer. Hepatology 47 919-928, 2008

22. Schatton T, Murphy GF, Frank NY, Yamaura K, WaagaGasser AM, Gasser M, Zhan Q, Jordan S, Duncan LM, Weishaupt $\mathrm{C}$, et al: Identification of cells initiating human melanomas. Nature 451: 345-349, 2008.

23. Sampieri K and Fodde R: Cancer stem cells and metastasis Semin Cancer Biol 22: 187-193, 2012.

24. Budd GT, Cristofanilli M, Ellis MJ, Stopeck A, Borden E, Miller MC, Matera J, Repollet M, Doyle GV, Terstappen LW, et al: Circulating tumor cells versus imaging - predicting overall survival in metastatic breast cancer. Clin Cancer Res 12: 6403-6409, 2006.

25. Sheng Y, Wang T, Li H, Zhang Z, Chen J, He C, Li Y, Lv Y, Zhang J, Xu C, et al: Comparison of analytic performances of Cellsearch and iFISH approach in detecting circulating tumor cells. Oncotarget 2015: 5, 2015. doi: 10.18632/oncotarget.6688.

26. Satelli A, Mitra A, Cutrera JJ, Devarie M, Xia X, Ingram DR, Dibra D, Somaiah N, Torres KE, Ravi V, et al: Universal marker and detection tool for human sarcoma circulating tumor cells. Cancer Res 74: 1645-1650, 2014

27. Ran R, Li L, Wang M, Wang S, Zheng Z and Lin PP: Determination of EGFR mutations in single cells microdissected from enriched lung tumor cells in peripheral blood. Anal Bioanal Chem 405: 7377-7382, 2013.

28. Chen Q, Ge F, Cui W, Wang F, Yang Z, Guo Y, Li L, Bremner RM and Lin PP: Lung cancer circulating tumor cells isolated by the EpCAM-independent enrichment strategy correlate with cytokeratin 19-derived CYFRA21-1 and pathological staging. Clin Chim Acta 419: 57-61, 2013.

29. Ning N, Zhan T, Zhang Y, Chen Q, Feng F, Yang Z, Liu Z, Xu D, Wang F, Guo Y, et al: Improvement of specific detection of circulating tumor cells using combined CD45 staining and fluorescence in situ hybridization. Clin Chim Acta 433: 69-75, 2014.
30. Miller AB, Hoogstraten B, Staquet $M$ and Winkler A: Reporting results of cancer treatment. Cancer 47: 207-214, 1981.

31. Enneking WF: Musculoskeletal tumor staging: 1988 update. Cancer Treat Res 44: 39-49, 1989.

32. Russell WL, Sailors DM, Whittle TB, Fisher DF Jr and Burns RP Limb salvage versus traumatic amputation. A decision based on a seven-part predictive index. Ann Surg 213: 473-480, discussion 480-481, 1991

33. Detry MA and Lewis RJ: The intention-to-treat principle: How to assess the true effect of choosing a medical treatment. JAMA 312: 85-86, 2014.

34. Xu SH, Yang YL, Han SM and Wu ZH: MicroRNA-9 expression is a prognostic biomarker in patients with osteosarcoma. World J Surg Oncol 12: 195, 2014

35. Yang J, Gao T, Tang J, Cai H, Lin L and Fu S: Loss of microRNA-132 predicts poor prognosis in patients with primary osteosarcoma. Mol Cell Biochem 381: 9-15, 2013.

36. Tang M, Lin L, Cai H, Tang J and Zhou Z: MicroRNA-145 downregulation associates with advanced tumor progression and poor prognosis in patients suffering osteosarcoma. Onco Targets Ther 6: 833-838, 2013.

37. $\mathrm{Mu} \mathrm{Y}$, Zhang $\mathrm{H}$, Che $\mathrm{L}$ and $\mathrm{Li} \mathrm{K}$ : Clinical significance of microRNA-183/Ezrin axis in judging the prognosis of patients with osteosarcoma. Med Oncol 31: 821, 2014

38. Zhang H, Yin Z, Ning K, Wang L, Guo R and Ji Z: Prognostic value of microRNA-223/epithelial cell transforming sequence 2 signaling in patients with osteosarcoma. Hum Pathol 45: $1430-1436,2014$

39. Tian Z, Guo B, Yu M, Wang C, Zhang H, Liang Q, Jiang K and Cao L: Upregulation of micro-ribonucleic acid-128 cooperating with downregulation of PTEN confers metastatic potential and unfavorable prognosis in patients with primary osteosarcoma. Onco Targets Ther 7: 1601-1608, 2014

40. Jentzsch T, Robl B, Husmann M, Bode-Lesniewska B and Fuchs B: Expression of MSH2 and MSH6 on a tissue microarray in patients with osteosarcoma. Anticancer Res 34: 6961-6972, 2014.

41. Sonaglio V, de Carvalho AC, Toledo SR, Salinas-Souza C, Carvalho AL, Petrilli AS, de Camargo B and Vettore AL: Aberrant DNA methylation of ESR1 and p14ARF genes could be useful as prognostic indicators in osteosarcoma. Onco Targets Ther 6: 713-723, 2013.

42. Zhu H, Tang J, Tang M and Cai H: Upregulation of SOX9 in osteosarcoma and its association with tumor progression and patients' prognosis. Diagn Pathol 8: 183, 2013.

43. Zhu Y, Zhou J, Ji Y and Yu B: Elevated expression of AKT2 correlates with disease severity and poor prognosis in human osteosarcoma. Mol Med Rep 10: 737-742, 2014.

44. Hu F, Wang W, Zhou HC and Shang XF: High expression of periostin is dramatically associated with metastatic potential and poor prognosis of patients with osteosarcoma. World J Surg Oncol 12: 287, 2014.

45. Zhu H, Cai H, Tang M and Tang J: Neuropilin-1 is overexpressed in osteosarcoma and contributes to tumor progression and poor prognosis. Clin Transl Oncol 16: 732-738, 2014.

46. Kubo T, Shimose S, Fujimori J, Furuta T, Arihiro K and Ochi M: Does expression of glucose transporter protein-1 relate to prognosis and angiogenesis in osteosarcoma? Clin Orthop Relat Res 473: 305-310, 2015.

47. Wang X, Du J, Gu P, Jin R and Lin X: Polymeric immunoglobulin receptor expression is correlated with poor prognosis in patients with osteosarcoma. Mol Med Rep 9: 2105-2110, 2014.

48. Dawood S, Broglio K, Valero V, Reuben J, Handy B, Islam R, Jackson S, Hortobagyi GN, Fritsche H and Cristofanilli M: Circulating tumor cells in metastatic breast cancer: From prognostic stratification to modification of the staging system? Cancer 113: 2422-2430, 2008.

49. Hayes DF and Smerage J: Is there a role for circulating tumor cells in the management of breast cancer? Clin Cancer Res 14: 3646-3650, 2008.

50. Liu MC, Shields PG, Warren RD, Cohen P, Wilkinson M, Ottaviano YL, Rao SB, Eng-Wong J, Seillier-Moiseiwitsch F, Noone AM, et al: Circulating tumor cells: A useful predictor of treatment efficacy in metastatic breast cancer. J Clin Oncol 27: 5153-5159, 2009

51. Krawczyk N, Banys M, Hartkopf A, Hagenbeck C, Melcher C and Fehm T: Circulating tumour cells in breast cancer. E Cancer Med Sci 7: 352, 2013 